\title{
Reforma administrativa: o caso do Reino Unido ${ }^{1}$
}

Marcelo Ernandez Macedo

Andrea Moraes Alves

\section{Introdução}

Com a eleição de um governo conservador em 1979, a Inglaterra assumiu a reforma administrativa como prioridade. Embora já constituísse tema de discussões desde os anos 60, a reforma da administração pública jamais havia alcançado tamanha valorização. Para a compreensão das propostas e medidas adotadas pelo governo Thatcher, as quais provocaram modificações substanciais na configuração do serviço público inglês, não podemos desprezar as especificidades desse país no que se refere às características do seu sistema político e ao estado anterior de sua administração pública.

No que se refere ao sistema político inglês, este caracteriza-se pela presença de um governo partidário, com a alternância de dois partidos que historicamente disputam o poder: os conservadores e os trabalhistas. A conseqüência imediata e fundamental desse modelo é que, invariavelmente, o sistema eleitoral atribui a maioria da Camâra dos Comuns a um dos partidos, o qual, ao escolher o primeiro-ministro, detém amplos poderes executivos. Além disso, alguns outros fatores que em geral limitam as prerrogativas do Poder Executivo - um Senado forte; uma constituição escrita; um sistema federativo; e um Judiciário ativo - estão ausentes no sistema britânico (CosTA, 1995:19). Portanto, apesar das tendências de flexibilização desse sistema, o modelo britânico fornece ao Poder Executivo um grau de autoridade para governar, pouco visto em regimes democráticos. Este modelo facilitou a implementação das reformas defendidas pelo governo conservador.

No que tange ao sistema administrativo inglês, um relatório apresentado pelo Comitê Fulton em 1968 marcou oficialmente o diagnóstico

Marcelo é mestre em administração pública EBAP/FGV/RJ e especialista em políticas públicas e gestão governamental no Ministério da Educação e do Desporto.

Andrea é socióloga e professora da Universidade de Brasília UnB 
negativo em relação à qualidade e à organização do serviço público na-

quele país. Além de críticas relativas à competência dos funcionários e à sua parcialidade no exercício das funções, o documento indicava a urgente necessidade de inserção de um approach técnico na formação dos funcionários, principalmente em relação à assessoria dos ministros, função ocupada pelos chamados generalistas. $\mathrm{O}$ argumento básico apontava para a necessidade de alcance da eficiência nas operações departamentais e da efetividade nas políticas públicas em lugar dos funcionários preocuparem-se com "a turbulência política do dia-a-dia" (ThomAs, 1984:245). No final dos anos 60, as idéias de eficiência e efetividade já conquistavam seu espaço no setor público provenientes de comparações com o desempenho de empresas privadas. A definição de objetivos e meios e a otimização dos recursos para alcance dos resultados esperados ascenderam como valores de um serviço público moderno.

Apesar das críticas, o Comitê Fulton não logrou abalar o prestígio que a tradição do serviço público britânico havia construído, nem fora esse seu objetivo. Reconhecia-se ainda a importância do trabalho dos generalistas que dominavam o conhecimento sobre o funcionamento do Parlamento e dos departamentos, tinham habilidades como coordenadores e estavam associados a uma história de estabilidade e honestidade no serviço público, estreitamente ligada à formação de um modelo administrativo burocrático no país, marca inconfundível do regime britânico desde o século XIX. ${ }^{2}$ Mas, as novas noções esboçadas no relatório do Comitê previam a exigência de um perfil mais profissional e menos político para os altos funcionários, caso contrário corria-se o risco de estagnação das atividades do aparelho do Estado diante dos novos desafios impostos pela economia e pela sociedade civil no mundo contemporâneo.

Uma década depois, com o advento dos conservadores ao poder, constatam-se as primeiras medidas efetivas com o objetivo de aumentar a eficiência e a efetividade dos serviços públicos, o que, no caso inglês, significa a adoção de um perfil técnico para os funcionários, a redução dos gastos públicos, o estabelecimento de metas de qualidade nos serviços e um reordenamento institucional da organização estatal que torne possível uma maior agilidade no cumprimento das funções públicas. Em última instância, visava-se instituir definitivamente os princípios do managerialism no setor público.

Pollitt (1996: 82) identifica três fases no processo de reforma administrativa iniciado por Margareth Thatcher. A primeira fase, que se estende de 1979 a 1982, caracteriza-se pela tentativa de redução de despesas. Para tal, $14 \%$ do total de servidores existentes em 1979 foram demitidos, e o Departamento do Serviço Civil, estrutura encarregada da administração de pessoal do governo, foi abolido, sendo substituído por uma nova estrutura (Management and Personnel Office - MPO) submetida diretamente 
ao gabinete do primeiro-ministro. O controle sobre o pagamento dos servidores passa a ficar a cargo do Tesouro. Inicia-se, ainda, nessa fase a implantação do "escrutíneos de Rayner", grupos de trabalhos ministeriais encarregados de racionalizar os gastos e eliminar os desperdícios.

Ciente das limitações políticas da simples proposta de redução de despesas, o governo passou a enfatizar a eficiência ao invés da economia. A nova ênfase de "fazer mais com menos" caracterizou a segunda fase das transformações implementadas pelos conservadores, a qual iria durar até o final de 1987. É dessa fase a ampliação para toda a administração do novo sistema de informações administrativas ( FMI - Financial Management Initiative - 1982); a implantação de um sistema de avaliação que introduziu metas a serem cumpridas por cada funcionário, além de um sistema de remuneração proporcional ao rendimento individual (1984/1985); e ainda o início de um amplo processo de privatização dos serviços públicos, operacionalizado tanto pela venda de diversas empresas como pela contratação externa para a prestação dos serviços, que iria expandir-se na fase seguinte.

A fase mais recente, iniciada com a terceira vitória consecutiva do Partido Conservador em 1987, caracteriza-se pela intensificação da utilização de mecanismos típicos de mercado; pela desconcentração na prestação dos serviços; pela retórica sobre a necessidade de qualidade no serviço público; e pelo direcionamento dos serviços para o consumidor. Dando continuidade à reestruturação institucional iniciada na segunda fase, efetivaram-se nesse período modificações substanciais na estrutura da administração pública através da instituição de novas formas de contratação. Atualmente, o serviço público britânico tem $65 \%$ do seu pessoal trabalhando em agências que ganharam relativa autonomia em relação ao poder central (JENKINS, 1996:90).

Apontados alguns tópicos importantes do processo de reforma administrativa na Inglaterra, é preciso ressaltar que, de acordo com o projeto de pesquisa elaborado por nossa equipe de trabalho, este texto não pretende reproduzir a história do processo de reformas administrativas na Inglaterra, mas analisar alguns aspectos específicos desse processo, quais sejam: formas inovadoras de gestão no setor público; a contratualização das relações nesse setor; e a política de gestão de recursos humanos, na qual se inserem os sistemas de avaliação de desempenho individual.

\section{Aspectos da reforma administrativa na Inglaterra}

A primeira forma inovadora de gestão no serviço público britânico, que merece ser analisada, é a formação dos "escrutíneos de Rayner". 
O primeiro governo Thatcher foi buscar no setor privado um consultor em administração, Sir Derek Rayner, com o objetivo de racionalizar os gastos e eliminar os desperdícios no serviço público. A partir de maio de 1979, Sir Rayner propôs dois tipos de exercícios: um particular ("escrutíneos"), relativo a investigações em funções e operações de cada departamento; e outro geral (“Lasting Reforms"), preocupado com reformas de caráter duradouro, que envolvem mudanças de comportamento para o exercício das atividades (THOMAs, 1984:241).

Os escrutínios, pequenos grupos formados por funcionários departamentais e assessorados por um grupo central ("Unidade de Eficiência"), esse por sua vez ligado diretamente ao gabinete do primeiroministro e chefiado pelo próprio Rayner, caracterizam-se pela realização de avaliações departamentais. As avaliações visam responder a três perguntas fundamentais para cada processo de trabalho examinado: 1) Quem é o responsável pelo processo? 2) Qual é o seu custo? 3) Quais são os resultados esperados? (JENKINs,1996:90). Os grupos departamentais têm três meses para produzir um relatório respondendo às questões. As decisões relativas às ações a serem implementadas são tomadas nos três meses seguintes, e os resultados devem efetivar-se completamente dentro de dois anos, a contar do início da avaliação.

A atuação de Rayner durante o período do escrutínio compreendeu o apoio e a orientação aos funcionários departamentais, o auxílio ao ministro na revisão do relatório e na elaboração do plano de ação (“Action Document"), e ainda o acompanhamento dos progressos de cada departamento, reportando-os ao primeiro-ministro. Durante 1980, 39 escrutínios foram identificados como potenciais economizadores de recursos, dos quais 24 , quando implementados, significaram economias de 22 milhões de libras por ano (Thomas, 1984:241). Alguns escrutínios serviram de modelo para transformações em processos semelhantes de outros departamentos, enquanto outros exigiram a cooperação entre departamentos, como foi o caso do escrutínio para o pagamento de benefícios a desempregados, o qual envolveu os departamentos de Emprego e o de Saúde e Seguridade Social.

Segundo Thomas (1984), uma das características que diferencia a abordagem de Rayner dos demais programas implementados desde 1960 é o arranjo político-administrativo ao qual essa abordagem está associada. Este arranjo compreende: envolvimento do ministro no escrutínio, o que garante o permanente interesse dos funcionários de alto nível; a independência dos funcionários departamentais encarregados do escrutínio em relação à rígida hierarquia de comando, e a importância dada pelo primeiroministro à essa ação, expressa pela vinculação da "Unidade de Eficiência" ao seu gabinete. Esse novo arranjo institucional representou a valorização do tema da eficiência como uma questão política e não meramente técnica. 
Não obstante, a associação entre as propostas de Rayner e as políticas conservadoras do governo geraram muitas críticas por parte dos sindicatos de servidores públicos. Os escrutínios são vistos como mecanismos de redução dos gastos públicos e do número de servidores públicos, e não como instrumentos de avaliação livres de valor. Essa imagem decorre do fato de que os escrutínios não foram efetivamente acompanhados por mudanças nas culturas organizacionais do serviço público. O exercício geral proposto por Rayner, "Lasting Reforms", parece não ter sido intensivamente praticado. Diversos autores criticam a pouca atenção dada à dimensão cultural das reformas. Até mesmo Kate Jenkins (1996:94), uma defensora ardorosa das reformas da era Thatcher, adverte sobre a confusão entre reformas administrativas e mudanças no rumo das políticas, alegando que as primeiras envolvem mudanças comportamentais, e que a falta de atenção para esse fato tem sido um dos principais equívocos das reformas.

A segunda forma inovadora de gestão diz respeito ao desenvolvimento de sistemas de informações gerenciais. Em 1979, Michael Heseltine, secretário do Departamento de Meio Ambiente, desenvolveu o MINIS (Management Information System for Ministers). Esse sistema de informação apresentava ao secretário do Departamento de Meio Ambiente toda a estrutura administrativa que o cercava, permitindo o questionamento de seu desenho e a identificação das responsabilidades e prioridades de cada subunidade. O MINIS, desenvolvido a partir de um exercício de Rayner, tornou-se um escrutínio permanente, que permitia ao secretário de Estado a revisão detalhada das atividades do departamento e das necessidades de recursos humanos.

No entanto, esse sistema enfocava principalmente os gastos com pessoal, omitindo informações a respeito das demais despesas administrativas, como diárias, viagens, postagem, telecomunicações, etc. A ausência de informações nesse sentido foi suprida pelos "estudos de Joubert", os quais resultaram no desenvolvimento do MAXIS ( Management Accounting System). Além da maior abrangência das informações, este sistema compreendia a criação de centros de custo locais, atribuindo a cada subunidade a responsabilidade pela administração de seu próprio orçamento. Segundo Thomas (1984), isso representou a principal mudança na forma de controle dos custos administrativos.

Restrito ao Departamento de Meio Ambiente, o Tesouro considerou que esses sistemas de informação poderiam ser estendidos para todo o serviço público. Em 1982, o governo anunciou o Financial Management Initiative (FMI) para cobrir todos os departamentos. Essa iniciativa representou a integração entre o MINIS e o MAXIS em escala ampliada. Os objtivos do FMI eram: 1) fornecer uma visão clara das metas e meios para alcançá-las, medindo os resultados parciais sempre que possível; 
2) definir responsabilidades para uma melhor utilização dos recursos, incluindo avaliações sobre os valores acrescentados por cada processo; 3) garantir o acesso à informação, principalmente em relação a custos e ao treinamento necessário para o exercício efetivo das responsabilidades.

O FMI foi operacionalizado da seguinte maneira: cada departamento foi chamado a produzir um plano para ser enviado ao MPO e ao Tesouro, o qual deveria conter informações a respeito dos programas, seus financiamentos e formas de controle, assim como sobre os responsáveis pela execução de cada um dos projetos; uma unidade de administração financeira, composta por membros do Tesouro e do MPO, trabalhou na orientação dos altos gerentes para a formulação de seus planos.

Em 1986, o FMI foi revisto e estendido com a finalidade de introduzir responsabilidades orçamentárias para os administradores de cada subunidade, incorporando definitivamente o princípio descentralizador preconizado pelo MAXIS. Inclusive, esta iniciativa parece ter sido a única efetivamente descentralizadora desde o início da era Thatcher.

No entanto, conforme alega Pollitt (1990: 55), tanto a respeito dessa iniciativa como também no que se refere ao pagamento por mérito e a contratação externa, o controle do governo central permaneceu forte. Ao estabelecer nos limites financeiros e as normas de performance para o repasse de recursos nos níveis locais, o governo conservador vem impondo obstáculos a uma descentralização genuína. Walker (1991:133) confirma essa avaliação quando argumenta que, ao reduzir o ritmo de repasse de recursos, e ao limitar as possibilidades dos entes locais em adquirir de forma autônoma os seus recursos, o governo conservador operou uma grande centralização fiscal. Conforme alega esse autor, tais iniciativas de centralização fiscal correspondiam a anseios de maior eficiência no serviço público e, como argumento legitimador, admitia-se que as administrações locais não estavam preparadas para gerenciar recursos autonomamente. Para o governo central, seria necessário que as administrações locais fossem mais prudentes, participativas e responsáveis na utilização dos seus recursos.

Uma terceira inovação no serviço público britânico, originada a partir de experiências locais trabalhistas em York e Lewhisham (Hood, 1994: 300), foi o programa Citizen's Charter. Os Charters correspondem a documentos nos quais são especificados objetivos e normas claros para cada serviço público, acompanhados dos recursos disponíveis para a sua execução, assim como a identificação dos responsáveis pela sua provisão. Esses documentos são destinados a informar ao usuário acerca do funcionamento dos serviços, sendo o primeiro documento elaborado ainda em 1981, o que, segundo Jenkins (1996:92), significou uma abertura em relação à tradição burocrática britânica de manutenção do sigilo sobre informações 
a respeito do serviço público. Os Charters são elaborados em torno de um conjunto de seis princípios:

a) divulgação dos padrões esperados pelos serviços e sua performance em relação a eles;

b) informação acurada, publicada em linguagem acessível, sobre a administração dos serviços, seu custo, seu desempenho e a definição das responsabilidades;

c) consulta sistemática ao usuário sobre os serviços, suas opiniões devem ser levadas em consideração na tomada de decisões;

d) os funcionários públicos têm o dever de serem corteses no tratamento do usuário, sem distinções de nenhuma espécie;

e) se algum erro é identificado, deve haver uma explicação e um meio efetivo de corrigí-lo. Os usuários devem ter acesso fácil aos locais de reclamação;

f) processamento eficiente e econômico dos serviços, dentro dos recursos que a nação dispõe. Deve haver uma validação independente da performance em relação a esse item.

O governo Major não tem medido esforços para ampliar o programa, o qual já se estendeu, inclusive, para os serviços privatizados (água, gás, eletricidade e telecomunicações). Em 1995, existiam 39 charters cobrindo os principais serviços públicos, alguns deles foram republicados, contendo padrões de qualidade mais elevados. Naquela época, estava previsto o lançamento de informações comparadas sobre a performance de escolas, hospitais e outros serviços locais. Já havia sido introduzido, em abril desse ano, um novo código para a elaboração de informação governamental, coordenado por um Ombudsman (MotTRAm ,1995:314).

Segundo esse autor, o Citizen's Charter tem resultado, em redução ao tempo de resposta às reclamações dos cidadãos, mecanismos de compensação mais satisfatórios para o consumidor, melhores sistemas de atendimento, e na introdução de leigos na supervisão dos serviços. Além disso, circula quinzenalmente um boletim informativo sobre os serviços públicos, e foi instituído um prêmio (The Charter Mark) destinado àqueles que alcançam níveis de excelência na prestação desses serviços, de acordo com os princípios estabelecidos pelo Citizen's Charter. São ainda elaborados documentos oficiais reportando o progresso dos padrões de qualidade estabelecidos.

Não obstante, pairam algumas críticas sobre essa iniciativa. A principal delas diz respeito ao caráter consumista do programa, problema assinalado tanto por Hood (1994) como por Pollitt (1996:83). De acordo com o segundo autor:

“Os cidadãos são pouco freqüentemente mencionados após o título - o foco principal localiza-se nos clientes e consumidores 
dos serviços ao invés de estar localizado num conceito coletivo de cidadania mais amplo e mais explicitamente político. Os administradores devem consultar os clientes e a partir daí estabelecer padrões para o serviço em questão. Acordos para participação coletiva ou representação dos cidadãos não são discutidos. $\mathrm{O}$ suposto parece ser o de que o cliente, que o governo tem em mente, é o individual, o consumidor que ativamente escolhe, ao invés do cidadão preocupado com o público. Certamente há pouca coisa no Charter que estenda direitos dos cidadãos ou arranjos coletivos, mesmo que os cidadãos possam demonstrar seu poder pela participação ativa." (tradução dos autores).

Observadas as críticas e os benefícios trazidos pelo programa, o fato é que o Citizen's Charter alcançou magnitudes inesperadas. Com 15 anos de duração, o programa encontra-se amplamente disseminado, abrangendo tanto os serviços estatais como os recentemente privatizados.

Antes de introduzir o tema das formas de contratação, parece importante dedicar algumas linhas ao amplo processo de privatização implementado na era Thatcher, já que, conforme veremos, estes dois temas estão fortemente imbricados.

A principal forma de privatização operada na Inglaterra foi a venda de ativos. Segundo Wright (1992:130), mais da metade do setor industrial pertencente ao Estado passou às mãos de agentes privados até 1992; mais de um milhão de empregados do setor público foi transferido para o setor privado; foram desnacionalizados os serviços de gás, eletricidade, água e telecomunicações, assim como as indústrias estratégicas (aeroespacial, siderúrgica, British Arways). O autor aponta alguns motivos para o voluptuosidade do processo de privatizações na Inglaterra: a imagem negativa do setor público; o fato de o governo central ser o proprietário das empresas; a inexistência de obstáculos constitucionais; a favorável posição comercial e financeira das empresas.

De acordo com Dunsire (1990:57/8), emergem duas conseqüências positivas do processo de privatizações na Inglaterra. A primeira delas advém da forma escolhida para a venda dos ativos, qual seja, a pulverização das ações das empresas entre os trabalhadores e a população em geral. $\mathrm{O}$ resultado disso é que em 1979 havia apenas 2 milhões de acionistas na Inglaterra, enquanto que em 1991 esta cifra alcançou os 13 milhões (WRIGHT, 1992:131). A segunda conseqüência positiva foi a significativa redução do déficit público.

Apesar das facilidades e conseqüências positivas enumeradas acima, alguns autores relutam em apontar o sucesso total do processo. No que se refere ao aumento de competividade após as privatizações, a maioria dos autores afirma que esse objetivo não foi alcançado. Dunsire 
afirma existir consenso na literatura quanto à idéia de que propriedade e estrutura competitiva são questões distintas; a propriedade, seja ela pública ou privada, não se constitui per si uma medida de competitividade. Segundo Vickers and Yarrow (in MARSH, 1991:466), devido à simplificação e à rapidez com que foi conduzido o processo, as falhas na efetiva introdução de mecanismos regulatórios e de promoção da competição impedem que o programa de privatização venha, a longo prazo, constituir-se num sucesso.

A respeito do aumento da eficiência e do comprometimento dos novos trabalhadores acionistas com as suas empresas, alega esse último autor que ainda são necessárias maiores investigações.

Todavia, a privatização na Inglaterra não se restringe à venda de ativos. Os textos que versam sobre esse tema enumeram diversas outras formas de privatização ocorridas nesse país: a desregulação, a supressão de serviços e investimentos públicos (na esperança de que o setor privado ocupe o espaço aberto), o aumento das taxas pagas pelo uso dos serviços. Além destas, destaca-se a contratação externa, tema sobre o qual nos debruçaremos a seguir.

No Reino Unido, durante muitas décadas, firmou-se a tradição da prestação de serviços por funcionários públicos. Os laborists acreditavam que assim se impedia o desemprego e regulava-se o setor privado. Por isso, os contratos com empresas privadas para a prestação de serviços públicos não tiveram um desenvolvimento importante até 1979.

Segundo Abrucio (1996:21), citando Clarke (1993), uma das medidas adotadas para operacionalizar a estratégia de tornar o poder público mais leve, ágil e competitivo foi a adoção de um novo modelo contratual para os serviços públicos. Esse modelo possui três dimensões:

a) a extensão das relações contratuais no fornecimento dos serviços públicos para o setor privado e para o setor voluntário não-lucrativo;

b) a extensão das relações contratuais dentro do serviço público;

c) o desenvolvimento de contratos de qualidade entre os provedores de serviços e os consumidores/clientes;

A primeira dimensão do novo modelo foi desenvolvida principalmente através da contratação externa. Desde o começo da era Thatcher até 1987, os conservadores haviam reduzido o emprego nos departamentos centrais em 22.000 postos de trabalho por intermédio das contratações externas de serviços ( REHFuss, 1991:174).

Um instrumento de contratação alternativo utilizado, e que integra a segunda dimensão acima citada, foi a "licitação competitiva", a qual permite que os próprios servidores públicos apresentem sua proposta para a prestação dos serviços, em competição com agências privadas. A facilidade de mobilização, o treinamento e a ajuda dos administradores das agências permitiram a organização de grupos de trabalho capazes de oferecer propostas para a execução de serviços, mantendo um mesmo 
nível de qualidade a custos reduzidos. Em 1983, exigiu-se dos entes sanitários distritais que os serviços de lavanderia, limpeza e assistência social fossem submetidos à licitação competitiva.

Dados coletados no Instituto de Administração de Pessoal mostram que, até 1986, os 522 contratos firmados pelo NHS - Nacional Health Service - junto a seus próprios funcionários resultaram em economias de 59.000, em média por contrato, frente às 140.000 libras, em média, economizadas com contratos privados. Os empregados próprios ganharam 78\% de todas as disputas (REHFuss, 1991:185).

Até 1988, no entanto, poucos serviços locais haviam se adequado ao novo modelo de contratação. Finalmente, em agosto de 1989, a administração central exigiu aos entes locais que fossem licitados os seguintes serviços: recolhimento de lixo; limpeza de ruas; manutenção de veículos; conservação de terrenos; escolas e edifícios. A cada seis meses, um dos itens desta lista deveria ser licitado.

A partir de um trabalho no qual entrevistou funcionários de diversas agências inglesas que vivenciavam processos de contratação, Rehfuss (1991) obtém pontos de vista bastante distintos a respeito das preferências desses funcionários. Enquanto alguns mostram-se satisfeitos com os serviços contratados externamente, outros prefeririam estar trabalhando com os antigos funcionários.

A principal preocupação dos contratantes a respeito dos contratados privados é com a queda na qualidade dos serviços prestados. É constatada a falta de experiência desses trabalhadores, que muitas vezes utilizam o seu primeiro contrato para a formação profissional, como conseqüência do fato de que no começo dos anos 80 , havia poucas empresas privadas prestadoras de serviço na Inglaterra, e essas empresas remuneram mal os seus trabalhadores, logo estes tendem a serem pouco qualificados. $\mathrm{O}$ Serviço Nacional de Saúde (NHS), por exemplo, após o fracasso inicial das experiências com contratos externos, tende atualmente a firmar contratos com os próprios funcionários (REHFUSS, 1991:180).

Ainda a respeito dos contratos firmados com agências formadas pelos próprios funcionários públicos, Pollitt (1996:83) afirma que as leis que governam as relações contratuais entre corpos públicos ainda não estão adaptadas à nova realidade administrativa, o que vem causando diversas ambigüidades na operacionalização dos contratos.

Em 1988, como resultado de um relatório da Unidade de Eficiência, foi concebido o Next Steps, uma iniciativa que, conforme o próprio nome indica, significa continuidade no objetivo de incrementar a eficiência no setor público.

O último objetivo do Next Steps era que três quartos dos servidores públicos passassem a trabalhar em unidades separadas do núcleo central do Estado, este responsável pela elaboração das políticas (WILSON, 
1991:23). Essas unidades seriam responsabilizadas pela execução das políticas públicas, teriam sempre um chefe executivo responsável pela sua performance, e as atividades seriam conduzidas a partir de contratos de gestão estabelecidos entre os departamentos e a administração central, esta representada pela Unidade de Eficiência. Pretendia-se atribuirlhes autonomia para a gestão administrativa e de recursos humanos, o que inclusive implicaria dificuldades para o sucesso do programa, dada à insistência do Tesouro em manter o controle centralizado dos recursos.

As agências têm, à disposição, quatro modelos de financiamento: a) Gross Running Costs, as agências têm seus orçamentos fixados; b) Net Running Costs, receitas e economias podem ser utilizadas para gastos administrativos adicionais; c) Trading Fund, um sistema de prestação de contas similar ao de uma organização comercial; e d) Governmentowned Company, totalmente independente do serviço público. É notável o fato de que a maioria das agências opera sob a forma de Gross Running Costs, nenhuma delas constituiu-se como Government-owned, duas têm Trading Funds (HMSO e Royal Mint) e cerca de doze operam sob a base de Net Running Costs.

Apesar de ter iniciado de forma tímida, em unidades administrativas pouco polêmicas e que tinha objetivos de fácil concretização, a proposta era que o programa se estendesse às mais diversas áreas. Conforme já vimos, hoje $65 \%$ dos servidores públicos britânicos trabalham em agências.

Em 1992, o governo Major iniciou dois novos processos de contratação conhecidos como Market Testing e Competing for Quality. Enquanto o primeiro selecionava serviços que poderiam ser prestados via "licitação competitiva", o segundo selecionava serviços que, estrategicamente, deveriam ser providos exclusivamente por agentes privados (MоттRAM, 1995:315). Em relação ao Market Testing, devido à inclusão no programa de serviços considerados estratégicos pelos funcionários de mais alto escalão, estes têm resistido a sua implementação, o que vem limitando o seu escopo (JENKINS, 1996:90).

Assim sendo, a adoção de novas formas de contratação significou a criação de um novo arranjo institucional no Reino Unido, o qual rompia com o antigo modelo de monopólio estatal, e aumentava o pluralismo institucional na provisão de serviços públicos. Não se tem hoje uma exata noção a respeito do futuro das agências públicas e privadas, apesar desse arranjo institucional já dominar a provisão dos serviços públicos. Enquanto alguns preferem o antigo modelo de prestação pública de serviços, outros agradecem por ver agências internas reforçadas.

Outro aspecto relevante da reforma administrativa britânica, intimamente associado às formas inovadoras de gestão e contratação, consiste na gestão de recursos humanos. 
Conforme vimos, o começo da era Thacher elegeu a administração de pessoal como um dos pontos básicos a serem reformados. As primeiras medidas foram a extinção do Departamento de Serviço Civil e a redução do quadro de funcionários.

O Departamento de Serviço Civil havia sido criado imediatamente após a publicação do Relatório do Comitê Fulton, com a responsabilidade de controlar o número de servidores e seu pagamento, e promover a eficiência gerencial através do acompanhamento do desempenho das atividades dos funcionários. Em suma, este órgão centralizava toda a gestão de recursos humanos. Em 1980, um comitê parlamentar apontou para a ineficácia do departamento, alegando sua falta de controle sobre algumas características básicas do quadro de pessoal. No final de 1981, a primeira ministra extinguiu o departamento, dividindo suas tarefas entre o Tesouro e uma nova unidade responsável pela gestão de recursos humanos, o MPO - Management and Personnel Office.

Ao MPO, estrutura interna ao gabinete da primeira ministra, couberam as tarefas de formulação, coordenação e supervisão da política de recursos humanos, seleção, recrutamento e treinamento de funcionários, assim como a promoção de estudos e pesquisas sobre organização e métodos. O Tesouro implementava o controle financeiro, a política de remunerações, e dimensionava os recursos humanos no setor público. Assim estava dividida a gestão dos recursos humanos em 1987, data que marca a extinção do MPO, com suas principais funções passando a ficar a cargo do Tesouro. A expansão do novo modelo de contratações (licitação competitiva e contratação externa) e a formação de centros de custos locais ensejou conflitos com o mecanismo centralizado (no Tesouro) de gestão de recursos humanos, então em vigor.

Ao lado de medidas relativas à alteração da estrutura organizacional, a política do governo conservador determinou mudanças em algumas características do funcionalismo público. Tradicionalmente, os servidores públicos britânicos eram selecionados através de exames competitivos e promovidos por mérito, havia uma clara distinção entre o serviço público e o interesse pessoal e uma marcante delimitação de funções e competências. Entre 1930 e 1960, verificou-se um substancial crescimento no tamanho e no escopo do trabalho dos funcionários, devido à cultura intervencionista do Welfare State, o fortalecimento da estrutura sindical, e a dispersão regional dos servidores.

O advento da administração conservadora em 1979 significou a intensificação de algumas medidas propostas pelo relatório Fulton no sentido de aumentar a accountability, o profissionalismo e a valorização do custo dos serviços. Butler (1993:398) afirma que as mudanças nas características do funcionalismo público podem ser observadas sob 
quatro perspectivas: vinculação (pública/privada), administração, competitividade e abertura.

No que se refere à vinculação dos funcionários, até 1993, quase um milhão de empregos no setor público foi transferido para a esfera privada. Apesar da ênfase inicial ter recaído sobre os funcionários das empresas estatais, recentemente o governo tem voltado sua atenção para a administração direta. De algo em torno de 732.000 funcionários em 1979 o setor público passou a possuir o efetivo de 580 mil em 1988 (DUNSIRE,1990:43).

Em relação à administração, as inovações administrativas e o novo modelo de contratação significaram mudanças importantes na organização do trabalho. De uma estrutura montada essencialmente sobre uma larga base horizontal, com departamentos monolíticos dividindo as mesmas condições de trabalho, pagamento e graus de hierarquia, operou-se a transformação em direção a uma base mais vertical, com o núcleo central encarregado pela elaboração das políticas públicas, e agências executivas pela sua implementação. Os funcionários departamentais passaram a ter maior liberdade em relação ao centro, enquanto aqueles situados nas agências executivas são balizados por relações contratuais que incluem objetivos, responsabilidades, pagamento, recrutamento e treinamento (BUTLER, 1993: 400).

Vale ressaltar a transformação exercida nos altos escalões. Enquanto num passado próximo os chefes de departamentos eram considerados intercambiáveis, podendo mover-se de um departamento para outro com facilidade, agora esses funcionários tornaram-se chefes de agências executivas, operando sob contratos pessoais firmados junto aos ministros, os quais possuem prazos, exame de performance e permitem uma maior remuneração de acordo com o desempenho.

Em relação ao treinamento dos funcionários, maior atenção parece que tem sido dada à formação para os altos escalões governamentais. Em 1985, o Civil Service College introduziu dois novos cursos: Top Management Programme e Senior Management Development Programme, ambos para funcionários em ascensão. Pollitt (1990:61) critica a negligência em relação à formação dos demais, apontando como motivos os constrangimentos econômicos e ideológicos que fazem parte do contexto do governo conservador.

No que tange à terceira perspectiva analisada por Butler (1993), a competitividade, o governo conservador, desde o início, não têm medido esforços para estimular a competição tanto entre os funcionários do próprio setor público (principalmente entre os de nível superior) como também entre estes e os do setor privado. As novas formas contratuais e as gratificações pela performance são os principais catalizadores para a competitividade. 
Essa terceira perspectiva influi diretamente sobre a quarta, qual seja, a abertura do serviço público. O aumento da competitividade, com a inserção de profissionais oriundos do setor privado na prestação de serviços públicos, minou a tradição de recrutar jovens universitários que fossem preparados para desenvolver uma carreira no serviço público. Entre 67 diretores de agência, citados no Whitehall Companion de 19931994, nenhum correspondia ao perfil clássico do diplomado em Oxford com uma carreira de generalista passada quase inteiramente dentro do serviço público (Hood,1994:305). Atualmente, a divulgação dos concursos públicos é muito mais ampla e os requisitos para a inscrição menos restritos. Somando-se a isso a democratização da informação gerencial (FMI), percebe-se hoje um significativo processo de abertura no serviço público.

Ainda no que se refere ao recrutamento dos funcionários, este agora é efetuado em nível departamental e das agências, sob a supervisão de uma comissão especializada, cujo papel restringe-se à salvaguarda dos princípios de justiça e competição aberta.

Outro ponto fundamental para a compreensão das inovações relativas à gestão de recursos humanos é a avaliação de desempenho dos funcionários. Item essencial, discutido desde o relatório do Comitê Fulton, o tema da avaliação de desempenho toma contornos mais definidos a partir de 1984, com a modificação do sistema anual de avaliação de pessoal em direção à introdução de objetivos para cada funcionário, cujo alcance ou frustração deveria ser discutido com a chefia.

O modelo pré-80 de pagamento dos servidores públicos britânicos era caracterizado por uma estrutura institucional durável, com um alto grau de centralização na determinação das condições de emprego e um estável processo de barganha, o qual envolvia diretamente as organizações sindicais. O governo comprometia-se em prover o equilíbrio entre uma remuneração considerada justa e o controle dos gastos públicos. Esse equilíbrio era constantemente negociado, baseado em uma comparação entre os ganhos salariais de empregados no setor privado e os salários e funções similares dos funcionários públicos. Havia uma unidade responsável por coletar dados que possibilitassem a comparação, a chamada Pay Research Unit (PRU). A partir do final dos anos 70 , esse sistema entrou em colapso devido à mudança no ambiente econômico e político.

No início da era Thatcher, desenvolveu-se uma preocupação com o controle dos gastos públicos, e, dois dos itens considerados fundamentais para esse controle diziam respeito ao número e aos proventos dos funcionários públicos. Quanto ao número, como já afirmamos, o corte no quadro de pessoal se deu imediatamente. Em relação aos salários, a busca por um novo modelo de determinação do pagamento vem, até hoje, causando controvérsias. 
O governo conservador estabeleceu dois princípios gerais para nortear o debate da questão salarial. O primeiro refere-se à importância de se ter um sistema estabelecido de pagamento; o segundo é a crença de que tal sistema deve responder às necessidades da eficiência gerencial, sendo totalmente comprometido com uma rígida disciplina de controle de gastos.

Nesse sentido, já em 1981, o governo revoga o PRU, sob o argumento de que o sistema, além de inflacionário, protegia os servidores públicos da concorrência benéfica ao mercado de trabalho. Para os conservadores, qualquer novo sistema deveria estar alicerçado em bases muito mais gerenciais.

Com a extinção do PRU, firmas de consultoria passaram a ser contratadas para a realização da pesquisa comparativa. Muito debate tem sido provocado entre consultores, governo e sindicatos acerca das metodologias de trabalho adotadas, da análise dos dados e de seu uso como parte do processo de negociação das políticas de pessoal. É importante ressaltar que não houve uma completa negação da comparação com o setor privado, em termos salariais e de condições de trabalho, mas o seu uso passou a ser visto como uma ferramenta gerencial que forneceria informações sobre níveis competitivos de pagamento, de forma a lidar com a necessidade de expansão ou de retenção dos quadros, e não mais como um instrumento político de barganha entre o governo e os sindicatos.

Em 1985, iniciam-se experimentos com bônus ligados à performance do funcionário - Performance Related Pay. Os servidores submetidos ao novo esquema encontravam-se nos níveis inferior e intermediário (graus 3 a 7) do serviço público. Em 1987, expande-se o novo modelo para o grau 2 da escala funcional. No entanto, essa expansão fragilizou-se já no ano seguinte, quando o Tesouro decidiu que aos servidores de graus 2 e 3 poderiam ser atribuídos pontos suplementares de remuneração de acordo com a vontade de seus chefes. Portanto, a proporção do salário submetida à avaliação do desempenho pôde ser compensada por este mecanismo discricionário.

Os servidores de grau 1, responsáveis pela elaboração das políticas públicas, não têm seus ganhos salariais afetados pela performance, com a exceção dos chefes de agências executivas. Quanto aos demais funcionários, que verdadeiramente sofrem os efeitos do pagamento relacionado à performance, a parte da remuneração ligada ao desempenho é recebida sob a forma de prêmios anuais que não possuem um caráter permanente. Não estando integrados ao salário, esses prêmios não contam para o cálculo da aposentadoria, representando apenas uma pequena parte do montante salarial desses funcionários (Hood, 1994, 303)

Como maneira de implementar a nova filosofia de pagamento, o governo começou a limitar o orçamento para inibir os aumentos do serviço 
público. Entretanto, houve necessidade de flexibilização dessa limitação, para evitar problemas com alguns grupos de funcionários.

As dificuldades enfrentadas pelo Performance Related Pay são exploradas por Ian Kessler (1993). Este autor argumenta que o tema tem sido cercado de incertezas e tensões, as quais envolvem, tradicionalmente, os sindicatos e o governo e, mais recentemente, as agências executivas e o Tesouro. O programa seria um mecanismo discricionário que estaria contribuindo para a erosão da moral dos servidores e de sua motivação para o trabalho, beneficiando alguns em detrimento de outros.

A avaliação da consultoria Hay MSL (KesSLER,1993,327) relata as visões dos funcionários sobre o sistema de pagamento, definindo-o como negligente, em relação ao estabelecimento de um firme critério de recompensas, e obscuro quanto aos procedimentos adotados.

Apesar disso, o governo conservador continua considerando a possibilidade de ligação entre a performance e o pagamento como um objetivo ótimo para equacionar os problemas de racionalização do gasto público. Para Kessler (1993), permanece em aberto o sucesso do governo em desenvolver o princípio do Performance Related Pay, não somente devido às resistências internas que dificultam a flexibilização, como também em relação ao convencimento dos funcionários de que o sistema promove maiores chances de realização profissional aliada à garantia da eficiência.

\section{Considerações finais}

Os resultados iniciais do processo de reforma administrativa na Inglaterra não permitem conclusões definitivas, dada a incerteza acerca do novo modelo de Estado proposto. Não obstante, dentro desse processo, dois pontos merecem ser destacados.

Em primeiro lugar, o próprio fato da reforma administrativa ser vista como um processo. Essa concepção possibilita a retomada constante dos caminhos da reforma, ocasionando avanços e recuos, e permitindo análises mais abrangentes sobre as medidas a serem tomadas. Todavia, ainda prevalece a idéia de que mudanças estruturais são capazes de promover transformações culturais. Conforme vimos, efetuaram-se modificações significativas na configuração do Estado, mas que parecem estar ainda longe de provocar uma substancial mudança cultural em direção aos princípios preconizados pelo gerencialismo. Alguns autores, como Hood(1994) e Poole et alli (1995), afirmam que alguns príncipios do gerencialismo já estão incorporados à prática dos servidores, enquanto outros, como Pollitt (1996), alertam sobre a debilidade das medidas acerca da formação e da satisfação dos prestadores de serviços públicos. 
O segundo ponto diz respeito ao caráter paradigmático do caso inglês. Isso se deve à transparência e à firmeza acerca da direção a ser seguida, além das conhecidas especificidades políticas e administrativas desse país. As medidas tomadas seguem nítida e publicamente a trilha do gerencialismo e da redução da presença do Estado em todos os âmbitos. Os defensores da proposta se esforçam para relativizar essa redução (rolling back the state), alegando que esta representa mais exatamente uma mudança de papel de um Estado provedor para outro regulador. Nesse sentido, essa nova configuração do Estado, massificada pelo adjetivo "neoliberal", tem o caso inglês como modelo.

Assim sendo, o caso inglês constitui-se num importante referencial de análise sobre o tema "reforma administrativa". Tanto pela observação das inovações gerenciais e contratuais adotadas, como através da sua proposta de gestão dos recursos humanos, a Inglaterra fornece exemplos que podem servir de parâmetro para as reformas em outros países. No entanto, é preciso ressaltar sempre a singularidade do processo inglês, evitando a transposição acrítica e descontextualizada de medidas isoladas. 
1 Este artigo foi realizado com recursos da ENAP Escola Nacional de Administração Pública. Constitui um dos produtos de pesquisa sobre Burocracia Estatal, do Programa de Pesquisas e Estudos sobre Reforma do Estado e governança, mantido pela FGV/ EBAP. Coordenado por Sonia Fleury, doutora em ciência política e professora de mestrado em administração pública da EBAP/FGV, e coordenadora do Programa de Estudos e Pesquisas sobre Reforma do Estado e governança mantido pela FGV/EBAP.

2 Referimo-nos propriamente ao chamado modelo Whitehall, cuja expressão encontrase no Northcote-Trevelyan Report of 1854 . Esse modelo baseia-se nos seguintes princípios: 1) divisão entre trabalho intelectual e tarefas mecânicas no serviço público; 2) concurso público; 3 ) promoções baseadas no mérito; 4) unificação dos departamentos, dentro dos quais promoções e transferências ocorreriam. (MarIon, 1993). 


\section{Referências bibliográficas}

ABRUCIO, Fernando Luiz. Impacto do modelo gerencial na administração pública: um breve estudo sobre a experiência internacional recente. ENAP, Brasília, 1996, mimeo.

BUTLER, Robin. The evolution of the civil service: a progress report. Public Administration, v.71, Autumn 1993, p.395-406.

CARTER, Neil. Learning to measure performance: the use of indicators in organizations. Public Administration, v.69, Spring 1991, p.85-101.

Costa, Valeriano Mendes F. Configuração do Atual Regime Parlamentarista Britânico. In: Andrade, Regis de Castro \& JACCoud, Luciana. Administração Pública Comparada: Grã-Bretanha, França, Itália e Alemanha. ENAP, Brasília, v.1, 1993.

Dunsire, Andrew. El Debate Público/Privado: Manifestaciones en el Reino Unido. Revista Internacional de Ciencias Administrativas, v.57, n.1, marzo 1990, p.33-69.

Greenaway, John. Having the Bun and the Halfpenny: Can Old Public Service Ethics Survive in the New Whitehall? Public Administration, v.73, Autumn 1995, p.357-374.

HaLl, Peter A. Policy Innovation and the Structure of the State: The Politics-Administration Nexus in France and Britain. ANNALS, AAPSS, 466, march 1983, p.43-59.

HEALD, David. Territorial Public Expenditure in the United Kingdom. Public Administration, v.72, Summer 1994, p.147-175.

Hood, Christopher. L'Evolution de la Gestion Publique au Royaume-Uni et la Suppression des Privilèges de la Fonction Publique. Revue Française d'Administration Publique, n.70, avril-juin 1994, p.295-308.

James, Simon. The Idea Brokers: The Impact of Think Tanks on British Government. Public Administration, v.71, Winter 1993, p.491-506.

Jenkins, Kate. Civil Service Reform in the United Kingdom. Seminário Internacional Reforma do Estado na América Latina e no Caribe, Brasília, maio 1996, mimeo.

KeRAUdRen, Philippe. Le Nouveau Management Public en Grande-Bretagne depuis 1979. Revue Française de Science Politique, v.43, n.04, août 1993.

Kessler, Ian. Pay Determination in the British Civil Service since 1979. Public Administration, v.71, Autumn 1993, p.323-340.

KNox, Colin \& McAlister, Denise. Policy Evaluation: Incorporating Users' Views. Public Administration, v.73, Autumn 1995, p.413-436.

Marion, David E. The British Civil Service: a Political Excavation and Review. Administration \& Society, v.24, n.4, february 1993, p.470-486.

Marsh, David. Privatization under Mrs. Thatcher: A Review of the Literature. Public Administration, v.69, Winter 1991, p.459-480.

Mascarenhas, R. C. Building an Enterprise Culture in the Public Sector: Reform of the Public Sector in Australia, Britain, and New Zealand. Public Administration Review, july-august 1993, v.53, n.4, p.319-328.

MCLAREN, Robert I. British Administrative Culture in the UN System. International Review of Administrative Sciences, v.60, 1994, p. 609-618.

Mottram, Richard. Improving Public Services in the United Kingdom. Public Administration and Development, v.15, 1995, p.311-318.

PollitT, Christopher. Managerialism and the Public Services. Oxford, Basis Blackwell, 1990.

. Antistatist Reforms and the New Administrative Directions: Public Administration in the United Kingdom. Public Administration Review, january-february 1996, v.56, n.1, p.81-87. 
Poole, Michael \& alli. Change and Continuities within the Public Sector: Contrasts between Public and Private Sector Managers in Britain and the Effects of the Thatcher Years'. Public Administration, v.73, Summer 1995, p.271-286.

Rehruss, John. La Agencia Competitiva: Reflexiones Generadas por la Contratación Externa en Gran Bretaña y Estados Unidos. Revista Internacional de Ciencias Administrativas, v.57, n.3, septiembre 1991, p.173-193.

RIDLEY, Frederick F. Intermediaries between Citizen and Administration: Some British Perspectives. International Review of Administrative Sciences, n.4, 1984, p.355-363.

Thomas, Rosamund. The Politics of Efficiency and Effectiveness in the British Civil Service. Revista Internacional de Ciencias Administrativas, n.3, 1984, p. 239-251.

. The Duties and Responsabilities of Civil Servants and Ministers: $a$

Challenge within British Cabinet Government. International Review of Administrative Sciences, v.52, 1986, p.511-538.

Walker, David B. Descentralización; Tendencias Recientes y Perspectivas desde un Enfoque Administrativo Comparado. Revista Internacional de Ciencias Administrativas, v.57, n.1, marzo 1991, p.127-147.

Wilson, Graham K. Perspectivas de la Función Pública en Gran Bretaña. Revista Internacional de Ciencias Administrativas, V.57, n.3, septiembre 1991, p.11-31.

Wright, Vincent. Les Leçons des Privatisations Britanniques ou les Dilemmes de L'Etat Libéral. Revue Française d'Administration Publique, n.61, janviers-mars 1992, p.127-133. 


\section{Reforma administrativa: o caso do Reino Unido \\ Andrea Moraes Alves e Marcelo Ernandez Macedo}

$\mathrm{O}$ artigo apresenta uma análise das principais características da reforma administrativa empreendida no Reino Unido a partir da do primeiro governo Thatcher em 1979. Inicialmente, são descritos dois aspectos peculiares que, segundo os autores, explicam a intensidade das reformas administrativas aí empreendidas: seu sistema político, no qual sobressai sobremaneira a alta capacidade decisória do Executivo, e as debilidades de seu sistema administrativo, alvo de críticas reiteradas desde o Relatório do Comitê Fulton, publicado em 1968. A partir disso, os autores descrevem três fases recentes na reforma administrativa inglesa pós-Thatcher. Nesta descrição, são enfocadas as principais características e experiências inovadoras adotadas, enfatizando, entre outros: 1) os chamados "escrutíneos de Rayner"; 2) os sistemas de informações gerenciais adotados (Management Information System for Ministers e o Management Accounting System); 3) o programa Citizen's Charter; 4) o processo de privatização inglês; 5) a experiência de contratação externa de serviços (com a adoção de instrumentos como a "licitação competitiva", que permite aos próprios servidores públicos apresentarem propostas para prestação de serviços em competição com as empresas privadas, além dos sistemas Market Testing e Competing for Quality) e, por fim; 6) a política de gestão de recursos humanos, com destaque para o forte processo de demissões no serviço público, o sistema de avaliação de desempenho dos funcionários e de remuneração por performance adotados no Reino Unido.

\section{Reforma administrativa: el caso del Reino Unido}

\section{Andrea Moraes Alves y Marcelo Ernandez, Macedo}

El artículo presenta un análisis de las principales características de la reforma administrativa emprendida en el Reino Unido a partir del primer gobierno Thatcher, en 1979.

Inicialmente se describen dos aspectos peculiares que, según los autores, explican la intensidad de las reformas administrativas que se emprendieron allí: su sistema político, en el que sobresale notablemente la alta capacidad decisoria del Poder Ejecutivo, y las debilidades de su sistema administrativo, blanco de críticas reiteradas desde el Informe del Comité Fulton, publicado en 1968. A partir de ello, los autores describieron tres fases recientes en la reforma administrativa inglesa post-Thatcher. En dicha descripción se enfocan las principales características y experiencias innovadoras adoptadas, enfatizando, entre otros 1) los llamados "escrutinios de Rayner": 2) los sistemas de informaciones gerenciales adoptados (Management Information System for Ministers y el Management Accounting System); 3)el programa Citizen's Charter; 4) el proceso de privatización inglés; 5) la experiencia de contratación externa de servicios (con la adopción de instrumentos como la "licitación competitiva", la cual permite que los propios servidores públicos presenten propuestas para la prestación de servicios, compitiendo con las empresas privadas, además de los sistemas Market Testing y Competing for Quality; y, por último; 6) la política de gestión de recursos humanos, realzándose el fuerte proceso de despidos en el servicio público, el sistema de evaluación del desempeño de los empleados y de remuneración según su performance, adoptados en el Reino Unido.
Revista do

Serviço

Público

Ano 48

Número 3

Set-Dez 1997

Marcelo é

mestre em administração pública $\mathrm{EBAP} / \mathrm{FGV} / \mathrm{RJ}$ e especialista em políticas públicas e gestão governamental no Ministério da Educação e do Desporto. Andrea é socióloga e professora da Universidade de Brasília - UnB 


\section{Administrative reform: the UK experience}

Andrea Moraes Alves and Marcelo Ernandez Macedo

This article analyses the main features of the administrative reform undertaken in the United Kingdom as of the first Thatcher Administration in 1979. Firstly, two specific aspects are described in order to explain the comprehensiveness of the administrative reforms carried out in the UK, namely its political system, in which the Execeutive Branch's high decison-making capability is particularly prominent, and the weaknesses of its administrative system, the target of repeated criticism since the Fulton Committee Report, published in 1968. Based on these points, a description is made regarding three recent phases in the post-Thatcher British administrative reform. The main features and innovative experiences are addressed, with special emphasis on 1) the so called Rayner scrutinies; 2) the management information systems used (Management Information System for Ministers and Management Accounting System); 3) the Citizen's Charter program; 4) the British privatization system; 5) the experience in contracting out services (through instruments such as competitive tendering, which allows civil servants themselves to advance proposals for services provision in competition with private companies, in addition to the Market Testing and Competing for Quality systems, and, finally, 6) the human resources management policy, underscoring the strong lay-off process in the civil service, the employee performance assessment and performance-based pay system used in the United Kingdom. 